\title{
O EMPREENDEDORISMO RURAL NA CAJUCULTURA: UM ESTUDO DE CASO
}

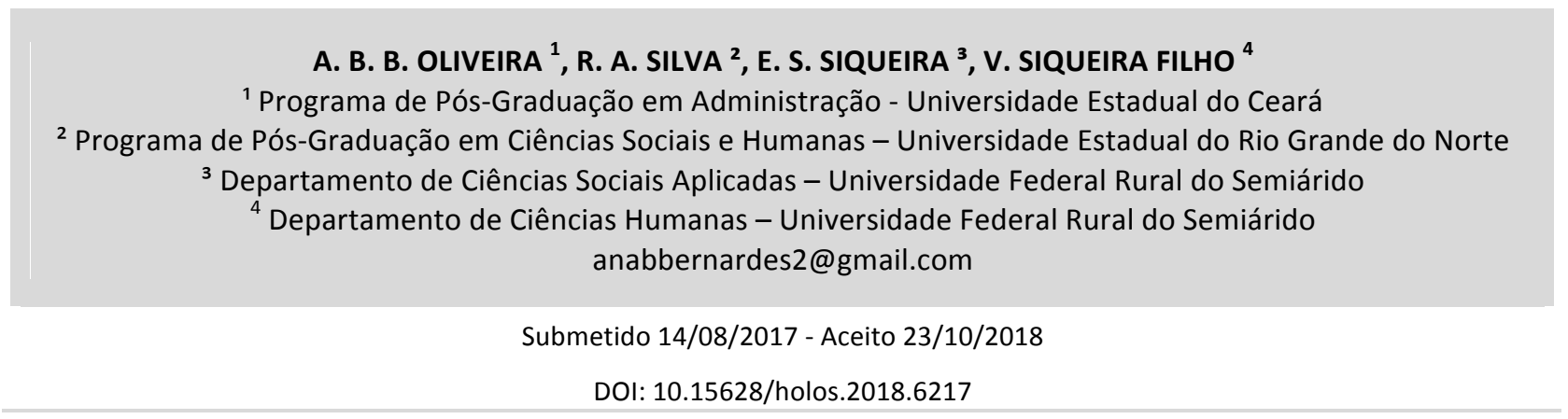

\section{RESUMO}

O presente trabalho tem como objetivo a identificação das estratégias gerenciais desenvolvidas pelos produtores de castanha de caju do município de Serra do Mel/RN, a fim de identificar se possuem características do empreendedorismo rural. As entrevistas foram realizadas com os produtores mais ativos de cada agrovila, totalizando 23 produtores. Constatou-se que os produtores têm um perfil empreendedor caracterizado pela persistência, pela

\begin{abstract}
ajuda mútua e pela capacidade de lidar com as incertezas e de aproveitar as oportunidades, obtendo, assim, êxito em seus negócios mesmo sem possuir conhecimento técnico aprofundado e acesso a novas tecnologias, sem recursos financeiros, com a incerteza oriunda da estiagem e sem incentivos governamentais. Eles enxergaram nesse meio de comercializar seus produtos uma estratégia para um desenvolvimento social, rural e econômico.
\end{abstract}

PALAVRAS-CHAVE: Cajucultura; Empreendedorismo rural; Inovação.

\section{RURAL ENTREPRENEURSHIP IN CAJUCULTURA: A CASE STUDY}

\begin{abstract}
The present paper has the objective to identify the management strategies developed by cashew nut producers of the municipality of Serra do Mel / RN. The interviews were conducted with the most active producers of each agrovila, totaling 23 producers. It has been found that producers have an entrepreneurial profile characterized by persistence, mutual aid, ability
\end{abstract}

to deal with uncertainties and seize opportunities, as they achieve success in their business even without indepth technical knowledge and access to new technologies, without financial resources, with the uncertainty arising from drought and without government incentives. They saw in this medium of marketing their products a strategy for social, rural and economic

KEYWORDS: Cashew cultivation; Rural entrepreneurship; Innovation. 


\section{INTRODUÇÃO}

No Brasil, em meados dos anos 1970, o meio rural começou a ter muitas transformações tecnológicas, sociais, políticas e econômicas, o que fez com que o setor agrícola fosse um dos mais ativos da economia brasileira. Atualmente, vários gestores acreditam que a solução para os diversos problemas sociais que enfrentamos, como o desemprego, moradia, entre outros, esteja no ambiente rural. No entanto, esse setor tem de acompanhar e se adaptar às mudanças econômicas que estão acontecendo constantemente; entretanto, para acompanhar essas mudanças, torna-se necessário que haja uma organização administrativa na propriedade (Arnould, 2011).

A inclusão econômica da agricultura está relacionada diretamente com dois segmentos. 0 primeiro é representado pelo setor de suprimentos de insumos utilizados na cadeia produtiva, o qual é caracterizado por um ambiente de mercado em que estão inseridos pequenos fornecedores que definem as regras de mercado e fornecimento de mercadoria à atividade agropecuária. O segundo segmento é caracterizado pelos agentes econômicos que dão apoio ao produto até a chegada à mesa do consumidor final. Esses agentes econômicos não interferem na formação dos preços; entretanto, a qualidade do produto que vai para a mesa do consumidor depende, essencialmente, do manejo de seu produto na propriedade (Miyazaki, Nazzari, Bertolini, Gaffuri, Schimitd, \& Teodoro, 2004).

Miyazaki et al. (2004) descrevem que o principal agente do desenvolvimento do campo é o produtor rural (agricultor e/ou pecuarista), e sua atividade é diferenciada das demais atividades econômicas por possuir características peculiares, as quais são descritas no trecho a seguir.

Ser exercida a céu aberto e, portanto, estar sujeita às influências climáticas de toda ordem; de uma forma geral não está em contato direto com o consumidor final; e, ainda, ser ou estar na condição de produtor rural, geralmente, não decorre de um processo de escolha do ramo de negócio, de forma análoga ao que acontece no meio urbano, pois a terra - o principal bem de produção na esmagadora maioria das vezes, é fruto do ato de legar, ou seja, passa de geração em geração, para potencializar o desenvolvimento rural (Miyazaki et al., 2004, p. 5).

Para que esse desenvolvimento rural ocorra efetivamente e traga bons resultados é necessário que o produtor rural seja um bom gerente, tenha conhecimentos sobre legislação, saiba aplicar de forma eficaz os recursos, entenda de meio ambiente e tecnologia, fatores esses essenciais para uma boa gestão (Arnould, 2011).

Conforme Veiga (2002), os estados brasileiros mais empreendedores no meio rural são: São Paulo, Paraná, Santa Catarina e Rio Grande do Sul. As chances de haver um desenvolvimento rural estão relacionadas à capacidade de empreendedorismo que, por sua vez, possibilita a geração de novos empregos, solucionando, dessa forma, alguns problemas sociais brasileiros.

Chaves, Magalhães, Benedetti, Blos e Silva (2010) relatam que a inserção de novos cultivos, de novos processos produtivos e de tecnologias no ambiente rural oferece desafios e dificuldades, principalmente no início, além de consideráveis investimentos financeiros. Os autores ainda destacam que o produtor rural precisa de uma quantidade muito grande de 
informações que necessitam ser estudadas, para formar uma estrutura de conhecimento que irá ajudá-lo a tomar uma decisão. E esse produtor rural passará por empecilhos em sua atividade, conforme destaca-se no trecho abaixo:

[...] a limitação organizacional e estrutural inerentes ao ambiente do empreendedor rural dificulta a tarefa de gerar informações gerenciais que permitam a tomada de decisão, com base em dados consistentes e reais. Dessa forma, o processo decisório no meio rural é muito mais baseado na criatividade, julgamento, intuição e experiência do administrador do que em métodos analíticos e quantitativos com suporte científico, não considerando praticamente nenhuma estatística dos dados disponíveis e muito menos a forma ideal para maximizar o lucro, claro que entendido aqui como o máximo possível e não o valor ótimo, conceito este derivado da economia (Chaves et al., 2010, p. 5).

O principal objetivo do produtor rural é permanecer no campo, inserido no agronegócio e mantendo cultura de subsistência, mas, por outro lado, conservando a ideia básica de maximizar os lucros. "Para que esse objetivo seja alcançado em tempos de globalização, se faz necessário que o produtor rural seja empreendedor e utilize as ferramentas administrativas o mais corretamente possível" (Arnould, 2011, p. 30).

Nesse contexto, este trabalho tem como tema o empreendedorismo rural e o campo de estudo terá como foco agricultores que se dedicam à cajucultura. Nos últimos anos, a cajucultura no Rio Grande do Norte tem enfrentado muitas dificuldades decorrentes da estiagem e pragas, conforme será discutido no referencial teórico. Contudo, a persistência das famílias produtoras em continuar produzindo e comercializando a castanha, assumindo riscos, e considerando que o empreendedorismo, na perspectiva schumpeteriana, está relacionado ao desenvolvimento econômico vinculado à capacidade dos empreendedores em conseguir legitimidade no mercado (Mendonça, Alves, \& Campos, 2010), a questão que se coloca neste estudo é se, diante de um cenário pouco promissor, os produtores têm conseguido criar alternativas para permanecerem na atividade fazendo uso de capacidades empreendedoras?

Dessa forma, o objetivo principal é a identificação das estratégias gerenciais desenvolvidas pelos produtores de castanha de caju do município de Serra do Mel/RN, a fim de identificar se possuem características do empreendedorismo rural.

\section{EMPREENDEDORISMO RURAL}

As expressões empreendedorismo, empreendedor e empreender têm origem na palavra francesa entrepreneur, originária do latim. No século XII, o termo estava associado à ação que o indivíduo tinha de impulsionar discórdias e gerar brigas; já no século XVI encontrava-se relacionado ao sujeito que assumia as responsabilidades e comandava uma ação militar. No entanto, foi somente entre o século XVII e XVIII que o termo foi empregado para designar uma pessoa que era criativa e comandava projetos e/ou empreendimentos (Schmidt \& Bohnenberger, 2009). 
Uma outra abordagem sobre o conceito foi apresentada por meio de estudos neoinstitucionalistas ${ }^{1}$, que passaram a designar a forma como os atores configuravam as instituições emergentes e modificavam as já existentes, apesar dos desafios e das complexidades. $O$ termo se originou na economia schumpeteriana, que define 0 empreendedorismo como uma engrenagem para o desenvolvimento econômico das nações, com a adesão de novas tecnologias e o imediato potencial para a obsolescência, fazendo com que os atores se adaptem às novas mudanças para assim sobreviverem. Dessa forma, os empreendedores passarão a concentrar seus empenhos para conseguir legitimidade no mercado e, assim, terão certa complexidade em se destacar no ambiente organizacional devido à heterogeneidade dos grupos sociais e seus objetivos. No entanto, à medida que esses empenhos se expandem, novos grupos surgirão e o processo de legitimação se estenderá (Mendonça et al., 2010).

Além de visão schumpeteriana, Gimenez, Ferreira e Ramos (2008) destacam a diversidade de perspectivas referentes ao empreendedorismo e apresentam três vertentes distintas e complementares, ilustradas em sínteses de três autores importantes na literatura sobre empreendedorismo: Schumpeter, Drucker e McClelland.

- Schumpeter e a ação econômica do empreendedorismo: Schumpeter visualizava o empreendedorismo como uma finalidade econômica, onde o fator preponderante é a inovação. Ele acreditava que as relações empreendedoras eram conduzidas pelo interesse em aquisição de bens. Ao tratar da Teoria do Desenvolvimento Econômico, Schumpeter concebia o empreendedorismo como fator principal desse desenvolvimento.

- $\quad$ Drucker e a ação administrativa do empreendedorismo: Peter Drucker acredita que a teoria do empreendedorismo faz parte do comportamento humano, e não é traço de personalidade, pois é considerada uma disciplina do conhecimento humano que pode ser obtida em nível individual e organizacional. Para ele, o empreendedor almeja por modificações, responde a elas e as identifica como oportunidades. No comportamento humano empreendedor, a inovação é a ferramenta peculiar, devendo ser cometida de modo sistemático pelo empreendedor. Essa inovação sistemática é o foco que Drucker nomeia de Administração Empreendedora, cuja concretização pode ser realizada em novas organizações e/ou organizações existentes e na gestão de serviços públicos. Para isso, é necessária a definição de ações empreendedoras que compreendem práticas relacionadas $a$ :

[...] (I) liderança da obsolescência dos produtos; (II) percepção do novo como de oportunidade e não ameaça; (III) trabalho no presente dos produtos que farão um amanhã diferente; (IV) estímulo às práticas empreendedoras com autonomia; (V) foco da visão administrativa em oportunidades; (VI) mensuração do desempenho inovador; e (V) criação de uma estrutura que permita a inovação (Gimenez et al., 2008, p. 25).

- McClelland e a ação comportamental do empreendedorismo: David McClelland também acredita que o comportamento é um dos fatores que alavancam o desenvolvimento

\footnotetext{
${ }^{1}$ Vertente da ciência política que enfatiza a autonomia relativa das instituições públicas, as possibilidades de ineficiência na história e a importância da ação simbólica para um entendimento da política (March \& Olsen, 2008. p. 1).
} 
econômico. Entretanto, o seu foco está em identificar a razão pela qual indivíduos específicos se envolvem com empreendimentos e outros não. McClelland acredita que o comportamento empreendedor é um dos diferentes papéis que o ser humano assume na vida social. A realização desse papel está relacionada à veemência de uma força central no comportamento empreendedor, que ele classificou de necessidade de realização.

Sintetizando as três vertentes, percebe-se que o aspecto principal do empreendedorismo é o seu teor inovador. Para Schumpter, o empreendedorismo possui uma finalidade econômica, possuindo um foco no empreendimento em si e se restringindo somente às empresas; para McClelland, é uma alternativa mais voltada para o comportamento do sujeito, enfatizando as empresas; e para Drucker, torna-se uma disciplina de aprendizagem, sendo utilizada em todos os tipos de organização (Gimezes et al., 2008).

Corroborando com Vale (2014), Ribeiro (2009) relata que no século XX alguns estudos já definiam o indivíduo empreendedor como aquele que atuava em mercados imperfeitos e que suas decisões eram duvidosas, já que estavam sujeitas a erros, devido à escassez de informações. Entretanto, o empreendedor também tinha o perfil de ser inovador, competitivo, ágil e perspicaz para aproveitar as oportunidades.

Corroborando com Dornelas (2010), Nogueira, Torres, Almeida, Ambrosio e Nogueira (2011) consideram que o empreendedor, de um modo geral, é um ser dotado de determinação, que cobiça conquistar novos espaços e desenvolver novos produtos e métodos de produção. Os autores ainda relatam o sucesso do empreendedor no trecho abaixo:

O empreendedor de sucesso pode ser considerado como o indivíduo que está sempre a observar negócios na constante procura por oportunidades, portador das condições necessárias para empreender e que busca absorver tudo o que contribui para a criação, desenvolvimento e realização da visão. A criatividade é orientada pela observação de outros negócios, associação de ideias, sucessos e fracassos (Nogueira et al., 2011, p. 3).

Embora o empreendedorismo seja um tema amplamente discutido, ainda não há um conceito consolidado (Martes, 2010; Guimarães, 2004). De acordo com Martes (2010), há 48 Journals acadêmicos sobre o tema envolvendo diferentes áreas do conhecimento, como Economia, Sociologia, Antropologia, Psicologia. Essa diversidade de abordagens também tem conduzido a uma categorização interna do conceito evidenciando diferentes tipos de empreendedorismo, como, por exemplo, empreendedorismo social (Oliveira, 2004), empreendedorismo feminino (De Jesus Santos, Muquiutti, Costa, Said, \& Junior, 2017), empreendedorismo institucional (Mendonça et al., 2010) e empreendedorismo rural (Tibério, 2016). Neste texto, será tratado apenas do empreendedorismo rural.

Ao desenvolver um estudo bibliométrico, baseado em 181 artigos publicados na base Scopus, no período de 1993 a 2013, Pato e Teixeira (2016) identificaram que, diferentemente do tema do empreendedorismo de forma ampla, a vertente do empreendedorismo rural é pouco abordada nas publicações acadêmicas. Os acadêmicos começaram a se interessar por esse tema na década de 1980. Contudo, até os anos 2000, a produção na área foi bastante incipiente, aumentando a partir desse ano gradativamente. Os autores do Reino Unido concentram o maior número de publicações na área, e os estudos abordam, principalmente, os países europeus em 
que o empreendedorismo passou a ser concebido pelas políticas industriais como um caminho para o desenvolvimento endógeno.

Ainda de acordo com Pato e Teixeira (2016), a predominância de estudos sobre o crescimento e desenvolvimento (macrotemas) migrou para outras abordagens, como traços psicológicos do empreendedor e características das organizações envolvidas (microtemas). Identifica-se que os temas emergentes a partir de 2000 estão relacionados à governança e à dimensão institucional.

A quadro 1, logo a seguir, apresenta o foco dos estudos apontados na literatura pesquisada.

Quadro 1 - Tópicos identificados na literatura sobre empreendedorismo rural

\begin{tabular}{|c|c|c|}
\hline & Tópico & Subtópico \\
\hline História e raízes do conceito & $\begin{array}{l}\text { Abordagens teóricas sobre } \\
\text { empreendedorismo rural }\end{array}$ & \\
\hline \multirow[b]{2}{*}{ Abordagem microeconômica } & $\begin{array}{ll}\text { Traços demográficos } & \text { do } \\
\text { empreendedor } & \\
\text { Questões psicológicas } & \text { dos } \\
\text { empreendedores } & \\
\end{array}$ & $\begin{array}{l}\text { Idade, origem, gênero } \\
\text { Motivação, habilidades individuais, } \\
\text { capital humano }\end{array}$ \\
\hline & $\begin{array}{l}\text { Características relacionadas às } \\
\text { organizações }\end{array}$ & $\begin{array}{l}\text { Inovação, tamanho, } \\
\text { internacionalização, setor, inovação } \\
\text { do produto/serviço, } \\
\text { desenvolvimento de mercados, } \\
\text { marketing, tecnologia de processo, } \\
\begin{array}{l}\text { uso/adoção de tecnologia da } \\
\text { informação }\end{array}\end{array}$ \\
\hline $\begin{array}{lll}\text { Abordagem } & \text { micro } & \text { e } \\
\text { macroeconômica } & & \\
\end{array}$ & $\begin{array}{l}\text { Embeddedness (enraizamento, } \\
\text { imersão) }\end{array}$ & Redes, laços sociais, cooperação \\
\hline \multirow{4}{*}{ Abordagem macroeconômica } & Ruralidade & $\begin{array}{l}\text { Características físicas, sociais e } \\
\text { econômicas }\end{array}$ \\
\hline & Crescimento e desenvolvimento & $\begin{array}{lll}\begin{array}{l}\text { Crescimento econômico } \\
\text { desenvolvimento }\end{array} & \text { e } \\
\end{array}$ \\
\hline & Políticas & Apoio, subsídio e financiamento \\
\hline & Marcos institucionais e governança & $\begin{array}{l}\text { Fatores socioculturais, autogestão e } \\
\text { capacidade institucional }\end{array}$ \\
\hline
\end{tabular}

Fonte: Adaptado de Pato e Teixeira (2016, p. 7).

Os dados apresentados por Pato e Teixeira (2016) sugerem a necessidade de aprofundar os estudos sobre o empreendedorismo rural, principalmente na construção de um conceito que considere as particularidades da dimensão rural.

McElwee (2006) também considera esse um campo de estudo em construção e defende que no empreendedorismo rural trata-se da transformação de agricultores em empreendedores. $\mathrm{O}$ avanço da competitividade demanda do agricultor capacidades funcionais para se ajustar a uma economia de mercado; contudo, considerando a necessidade de redução de risco nas áreas rurais, a organização e o apoio do governo e da comunidade local são fundamentais. 
Nesse contexto, a definição de empreendedorismo rural assume algumas características singulares. $O$ empreendedor rural é aquele que se ocupa em tempo integral das atividades relacionadas a sua propriedade, mas que, além do gerenciamento, sua preocupação relaciona-se com a inovação. Nesse sentido, envolve risco, criatividade e inovação.

Tibério (2016) propõe uma distinção conceitual. Para a autora, o empreendedorismo rural difere de empreendedorismo em espaço rural. Enquanto a primeira abordagem tem uma relação endógena com o lugar, ou seja, uma preocupação com o desenvolvimento sustentável da empresa e da região; a outra tem como perspectiva preponderante os resultados da empresa de forma desarticulada com o desenvolvimento da região. Portanto, a dimensão local seria uma característica importante no conceito.

Nesse contexto, enquanto McElwee (2006) apresenta uma abordagem mais empresarial vinculada à dimensão da competitividade, Tibério (2016) acrescenta a vertente da responsabilidade social, vinculada ao desenvolvimento local.

Essa relação com a economia local também é abordada por Henderson (2002), que considera que o empreendedorismo rural varia de acordo com dois fatores gerais: indústria e geografia. Algumas indústrias, que se interacionam com o meio rural, são mais propícias à inovação, assim como algumas comunidades têm maior capacidade de superar suas limitações. Dessa forma, a eficiência do empreendedorismo rural não se limita a características individuais, mas dependem de um contexto. $\mathrm{O}$ autor considera que existem empreendedores rurais de alta performance e outros que, decorrentes das dificuldades relacionadas ao mix indústria e geografia, não conseguem se desenvolver. Na perspectiva do autor, as políticas governamentais devem apoiar os empreendedores de alto desempenho, para tanto cita o caso dos Estados Unidos da América, que desenvolvem quatro tipos de políticas de desenvolvimento empresarial: melhorar as habilidades empreendedoras individuais, fortalecer as comunidades, propiciar recursos e criar redes que contribuam para que os empreendedores captem recursos.

McElwee (2006) sugere também algumas alternativas, contudo, sem levar em consideração o tipo de desempenho obtido pelo empreendedor: intensificação da produção convencional por aumento de volume com eficiência e eficácia, diversificação, inclusão de negócios não agrícolas, integração direta ou reversa da cadeia de valor, participando de processamento de alimentos, marketing direto, produção orgânica, redução de custos e arranjos cooperativos. $\mathrm{O}$ autor considera que essas estratégias de mudança se constituem como práticas empreendedoras.

O estudo de McElwee (2006) fornece uma ampla descrição do empreendedorismo rural. Considera que a dificuldade em estabelecer os parâmetros de análise repousa no fato de que agricultores não são um grupo homogêneo dificultando o desenvolvimento de políticas. Ainda que em empresas menores as características do empreendedor desempenhem um papel relevante, tal fato não desconsidera que os agricultores precisam pensar estrategicamente e agir a partir de habilidades empreendedoras, o que demanda ênfase na educação e no treinamento.

\subsection{A Cultura do Caju}


O cajueiro (Anacarduim occidentale L.) é uma planta tropical originária das regiões Norte e Nordeste do Brasil. Propagou-se em outras nações, principalmente Nigéria (660.00 t), Indonésia (142.536 t), Vietnã (1.190.600 t) e Índia (665.000 t), que são responsáveis por mais da metade da produção mundial de castanha (FAO, 2015), incluindo entre essas nações o Brasil, com 239.702 toneladas.

A prática de comercializar o caju e seus derivados, além de um conjunto de diversas atividades que dá origem a vários produtos intermediários e finais, denomina-se cajucultura. "O principal produto final gerado é a Amêndoa ${ }^{2}$ da Castanha de Caju (ACC), retirada do processamento da castanha (verdadeiro fruto), que também da casca da castanha é obtido o Líquido da Castanha de Caju (LCC), de elevado valor comercial". Já o pedúnculo é utilizado no processamento de bebidas, como cajuína, sucos e outros produtos, como ração animal e doces. Entretanto, estima-se que $90 \%$ dos pedúnculos sejam descartados, ou seja, "trata-se de um subproduto pouco aproveitado na cadeia da produção de castanha" (CONAB, 2013, p. 1).

A figura 1 ilustra como se subdivide o caju.

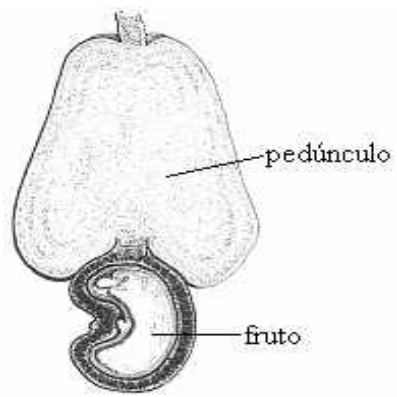

Figura 1 - Divisão do caju

Fonte: Sobiologia (2015).

Desse modo, a grande maioria dos produtores de caju torna-se fornecedora de castanhas. Ainda nas propriedades rurais, a castanha é separada do pedúnculo, secada ao sol e comercializada, na maioria das vezes, por agentes atravessadores (intermediários). Os grandes produtores, por possuírem maiores recursos de entrega, acabam conseguindo vender a castanha diretamente às indústrias de processamento (Figueiredo, Souza Filho, \& Guanziroli, 2015). As indústrias de alimentos, principais compradores internacionais, realizam a torra e a salga para a venda no mercado, assim como utilizam o produto na composição de outros alimentos (Souza Filho, Guanziroli, Figueiredo, \& Valente Júnior, 2009). No mercado nacional, quem realiza esse processo de beneficiamento são os próprios produtores rurais, as pequenas indústrias e as cooperativas.

A comercialização da cajucultura iniciou-se no Nordeste na década de 1970, através de incentivos da Superintendência de Desenvolvimento do Nordeste (Sudene). Na época, foram utilizados dois projetos de incentivos fiscais: o Fundo de Investimento do Nordeste (Finor), que foi utilizado para o desenvolvimento da indústria responsável pelo processamento da castanha, e o Fundo de Investimentos Setoriais (Fiset), que foi utilizado para subsidiar o reflorestamento dos

\footnotetext{
2 "Parte comestível da castanha de caju, formada por dois cotilédones de cor marfim, que por processo mecânico adequado, teve retiradas sua casca e película" (Jucá, 2014, p. 33).
} 
cajueiros. Esses incentivos viabilizaram a plantação de aproximadamente 300 mil hectares de cajueiro gigante e a instalação de indústrias processadoras de castanha em Fortaleza, Teresina e Mossoró (Guanziroli, Souza Filho, \& Valente Junior, 2015).

Outro fator primordial envolvido na plantação de cajueiros no semiárido brasileiro é a estratégia socioeconômica, que se ajusta ao modelo de exploração das culturas de subsistência (milho, mandioca e feijão) no espaço e no tempo, como uma fonte de renda, e viabiliza as atividades desses produtores no período de entressafras dessas culturas, além de ter um desenvolvimento produtivo elevado sob condições climáticas de baixo regime pluvial e em épocas de sequeiro (Moreira, 2011).

Gomes (2007) também elucida que o agronegócio do caju, em contexto nacional, encontra-se mais concentrado na região Nordeste, mais especificamente nos estados do Ceará, Rio Grande do Norte e Piauí. Fatores como a adaptação dos cajueiros ao clima nordestino, os adventos tecnológicos para aumentar a produtividade, tanto dos segmentos produtores de matéria-prima quanto dos processadores, e o aprimoramento de novos produtos derivados do caju viabilizam as possibilidades de desenvolvimento dos estados nordestinos através dessa atividade.

Nos estados do Ceará, Rio Grande do Norte e Piauí concentram-se pouco mais de 700 mil hectares de plantação, onde são colhidos mais de $90 \%$ da produção e processamento nacional de castanha. A maior área plantada com a cultura do caju está no estado do Ceará, com aproximadamente 400 mil hectares, seguida do Piauí, que gira em torno de 185 mil, e pelo Rio Grande do Norte, que possui 120 mil. Os principais mercados consumidores da amêndoa brasileira são Canadá e Estados Unidos, representando quase 85\% das exportações. Esses fatores contribuem para que o capital de giro em torno do agronegócio do caju no mundo seja cerca de 2,4 milhões de dólares por ano (MMA, 2015).

Conforme o IBGE (2013), no estado do Rio Grande do Norte, as cidades que possuem mais áreas destinadas à produção do caju são: Serra do Mel (28.000 ha), Macaíba (12.000 ha), Apodi (6.800 ha), Mossoró (6.645 ha) e Touros (4.500 ha). No entanto, a produção de Macaíba se destaca com 6.000 toneladas, seguida por Serra do Mel, com 2.240 toneladas, Apodi, com 2.041 toneladas, e Mossoró, com 1.993 toneladas. Desse modo, no ano de 2013 as cidades lucraram

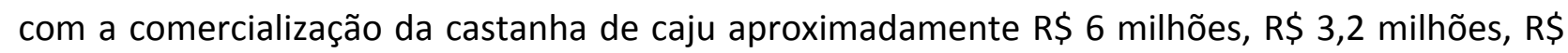
2,5 milhões e R\$ 3 milhões, respectivamente.

Algumas cidades potiguares têm sofrido um declínio em suas produções devido a fatores como a morte dos cajueiros, pragas e, principalmente, a seca que atinge a região do semiárido há mais de quatro anos (BNB, 2010). Conforme o pesquisador João Maria Pinheiro de Lima, da Embrapa Fruticultura e da Empresa de Pesquisa Agropecuária do Rio Grande do Norte (Emparn), a oferta de castanha de caju caiu entre $70 \%$ e $80 \%$ nesses últimos anos na região do semiárido, onde estão localizadas as principais cidades produtoras, Apodi, Mossoró e Serra do Mel. O pesquisador ainda explica que, mesmo que o clima melhore, a produção não voltará à normalidade em curto prazo, e o que agrava mais a realidade é o impacto negativo na renda das famílias rurais e a escassez de alternativas urgentes (EMPARN, 2015). 
Serra do Mel é o munícipio mais prejudicado, pois a cajucultura é a sua principal fonte econômica. Carvalho (2015) afirma que o cultivo de caju na Serra do Mel vem sendo prejudicado por dois fatores: a invasão da mosca-branca ${ }^{3}$ e a estiagem. A expectativa é que o volume de produção de castanha não atinja $10 \%$ do volume médio que é produzido em períodos de bom inverno. Em tempos de chuva, a produção ultrapassa as 15 mil toneladas. Alves (2015) relata em seu texto intitulado "Serra do Mel: de próspera a um cenário cinza" que a realidade de Serra do Mel é delicada, considerando que quase $50 \%$ dos cajueiros já morreram.

Entretanto, mesmo com essas dificuldades e queda na produção, as famílias ainda continuam produzindo. Produtores que costumavam colher cerca de 12 mil quilos, em épocas de chuvas, atualmente esperam por uma produção de 1.500 quilos de castanha. No entanto, as famílias se mostram otimistas em relação às mudanças climáticas, que a produção volte a ganhar destaque e que haja mais incentivos políticos, como a elaboração de medidas que estimulem a produção e a disponibilização de recursos financeiros, entre outros métodos que tentem reverter a situação atual (Carvalho, 2015).

Algumas medidas já começaram a ser implantadas para tentar contornar a realidade negativa da cajucultura no município. O Instituto de Desenvolvimento Sustentável e Meio Ambiente (IDEMA, 2015) destaca que um Comitê Gestor designado pelo Governo do Estado elaborou um projeto de revitalização da cadeia produtiva do caju. Esse plano de ação contém diversas práticas de alternativas agropecuárias e assistência técnica, implementação de métodos tecnológicos atuais, entre outras soluções vigentes para recuperar o cultivo de caju em Serra do Mel.

\section{METODOLOGIA}

\subsection{Tipo de Pesquisa}

O delineamento da pesquisa foi teórico-empírico. Desse modo, foi realizada por meio de pesquisa de campo no contexto do empreendedorismo rural e produção de castanha de caju.

Qualifica-se como uma pesquisa descritiva. "As pesquisas descritivas têm como objetivo primordial a descrição das características de determinada população ou fenômeno ou, então, o estabelecimento de relações entre variáveis" (Gil, 2007, p. 42). Portanto, as pesquisas descritivas são aquelas que descrevem os fatos ocorridos com maior frequência em um dado campo de pesquisa.

Para o desenvolvimento da pesquisa usou-se uma abordagem qualitativa. Para Moura e Ferreira (2005, p. 79), "Os dados qualitativos apresentam-se sob a forma de descrições

\footnotetext{
3 “A mosca-branca é um inseto sugador, de importância econômica mundial, pertencente à família Aleyrodidae, com cinco gêneros principais: Bemisia, Aleurothrixus, Dialeurodes, Trialeurodes e Aleurodicus. É praga polífaga de alta capacidade reprodutiva, presente em mais de 300 plantas hospedeiras e manifesta alta resistência aos inseticidas tradicionais utilizados nas Américas. As injúrias podem ser causadas por adultos e ninfas por meio da sucção da seiva e, indiretamente, pela disseminação de vírus fitopatogênicos e favorecimento do crescimento do fungo conhecido como fumagina, que se desenvolve nas substâncias açucaradas (honeydew), excretada pelo inseto. No Brasil, dentre outras espécies, destaca-se Aleurodicus cocois, conhecida popularmente como a mosca-branca-do-cajueiro ou 'mosca branca gigante'" (Vieira, 2007, p. 1).
} 
narrativas, resultantes, em geral, de transcrições de entrevistas estruturadas ou semiestruturadas e de anotações provenientes de observações livres ou assistemáticas".

A fim de atender aos objetivos propostos, a técnica de pesquisa utilizada neste trabalho se deu por meio das seguintes etapas: identificação do maior produtor de cada vila, coleta de dados com aplicação de entrevista, quantificação dos dados, tratamento e análise dos dados.

\subsection{Local de Estudo}

O campo de estudo foi escolhido por motivos de a cajucultura ser a principal fonte de renda do município de Serra do Mel/RN, assim como uma melhor acessibilidade e a disponibilidade dos produtores em ajudar no procedimento da pesquisa.

\subsubsection{Caracterização do campo de estudo}

Situada entre Assu e Mossoró, e entre o sertão e o litoral, a localidade já era referenciada pelos caçadores da região como Serra do Mel, em decorrência da grande quantidade de mel silvestre produzido pelas abelhas existentes em abundância na região. O lugar faz parte de um projeto de colonização instituído pelo então governador Cortez Pereira em 1970, mas só foi implantado em 1972 (IBGE, 2013).

O povoamento na região de terras produtivas é recente. Os primeiros resultados foram obtidos somente após a produção agrícola vigente do projeto de colonização. Com isso, foram chegando muitos agricultores de cidades vizinhas, que habitaram naquelas terras, as quais, futuramente, se tornariam uma cidade. Dentro de poucos anos, Serra do Mel passou a ser um grande depósito do Rio Grande do Norte, através do projeto estimulador da prática do cooperativismo e da agroindústria com a cajucultura (IBGE, 2013).

Devido ao povoamento, a localidade então passou a ser dividida em 23 vilas de produção; cada vila é denominada com o nome de um estado brasileiro. Voltada para uma produção organizada através do cultivo de terras e com uma economia alicerçada no cooperativismo, Serra do Mel ganhou destaque na exportação de castanha de caju.

Serra do Mel conquistou sua autonomia política no dia 13 de maio de 1988, quando teve suas terras desmembradas de Areia Branca, Assu, Carnaubais e Mossoró, tornando-se um município do estado do Rio Grande do Norte.

Em 2014, Nunes, França, Silva, Sá e Gurgel (2018, p. 193) realizaram uma pesquisa de campo na cadeia da cajucultura no território Assu-Mossoró. A pesquisa constatou que, nos municípios de Assu, Mossoró e Porto do Mangue, as unidades de corte de castanha são individuais, e somente o município de Serra do Mel possui $1 \%$ de fábrica e se encontra com a estrutura adequada para a produção. Nesse contexto, Andrade Neto (2006, p. 22) acrescenta:

Serra do Mel - RN, município originário de um projeto de colonização agrícola, tem sua base econômica centrada na produção de castanha de caju, em regime de economia familiar. Porém, é a industrialização da castanha de caju em unidades familiares que diferencia os pequenos produtores da Serra do Mel dos demais agricultores familiares em todo o nordeste brasileiro, já que seus produtores de castanha de caju desenvolveram, a partir de 1989, uma tecnologia alternativa de sistema de 
beneficiamento descentralizado de castanha de caju, adaptando a tecnologia industrial para uma mini-indústria familiar.

Até 2014 , as famílias produtoras que habitam na cidade, conforme estimativa do IBGE (2014), são cerca de 11.500 pessoas, estão enfrentando problemas de estiagem e pragas agrícolas, fatores que fizeram a produção de caju cair drasticamente.

\subsection{Sujeitos da Pesquisa}

Participou da pesquisa o maior produtor de cada vila, totalizando 23 produtores. A indicação dos sujeitos ocorreu mediante conversas com os produtores locais, que indicaram aqueles que tinham maior destaque na produção, considerando tanto volume como permanência no mercado.

Os entrevistados são todos do sexo masculino, naturais de cidades do Rio do Grande do Norte, como Baraúna, Carnaubais, Martins, Lajes do Cabugi, Catolé do Rocha, entre outras.

Alguns produtores possuem uma renda mensal de aproximadamente $\mathrm{R} \$ 20.000,00$, sendo que o produtor da vila Brasília, por exemplo, declarou uma renda média anual de mais de $\mathrm{R} \$ 100.000 .00$.

Dos entrevistados, 10 possuem o segundo grau completo, 6 possuem o primeiro grau completo, 2 possuem o primeiro grau incompleto e 5 são alfabetizados. Doze têm filhos em idade escolar estudando e 5 têm filhos que possuem o ensino superior, geralmente em cursos de Pedagogia, Letras e Enfermagem.

A figura 2 ilustra o nível de escolaridade dos produtores estudados.

Figura 2 - Nível de escolaridade dos produtores

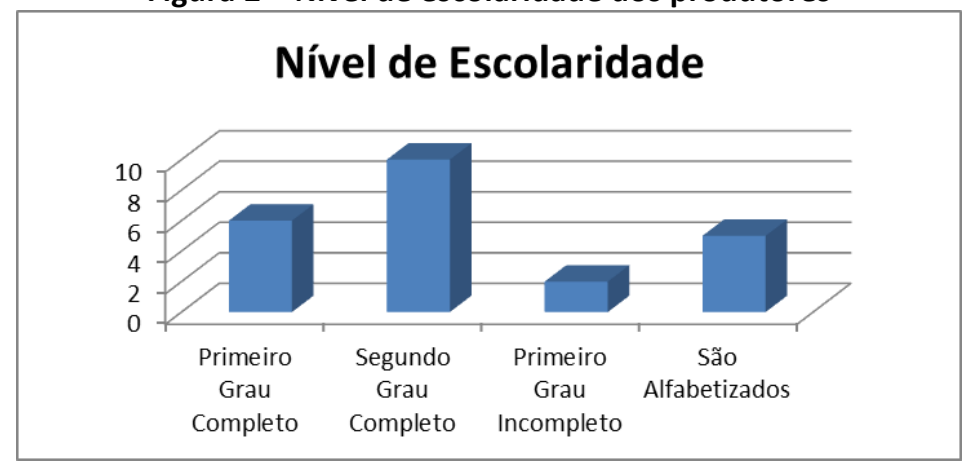

Eixo $x$ - Número de produtores

Eixo y - Níveis de escolaridade

Fonte: Elaboração dos autores (2018).

\subsection{Instrumento de Coleta de Dados}

Foi utilizado um roteiro semiestruturado que continha 19 questões dividido nas seções apresentadas no quadro 2. 


\section{Quadro 2 - Roteiro da entrevista}

\begin{tabular}{|c|c|}
\hline Seções & Questões \\
\hline Origem & Fale um pouco sobre as origens da sua família. \\
\hline Educação & $\begin{array}{l}\text { Vocề pode me falar um pouco sobre a sua formação? Vocề } \\
\text { estudou até qual série? } \\
\text { Seus filhos estão estudando? } \\
\text { Algum membro da família possui nível superior? Em quê? }\end{array}$ \\
\hline Conceitos de si & $\begin{array}{l}\text { Como vocề se vê como pessoa? } \\
\text { Quais, em sua opinião, são suas características mais importantes } \\
\text { para o seu negócio, a comercialização do caju? } \\
\text { Como surgiu a ideia de plantar e comercializar o caju? } \\
\text { Conte-me sobre seus primeiros passos nesse empreendimento. }\end{array}$ \\
\hline Produção do caju & $\begin{array}{l}\text { Relate como é o processo de comercialização do caju, desde o seu } \\
\text { plantio até a venda. } \\
\text { Qual a sua função nessa cadeia produtiva? Você̂ somente planta } \\
\text { e/ou vende ou é apenas atravessador? } \\
\text { Quais os maiores obstáculos enfrentados na sua } \\
\text { produção/comercialização? }\end{array}$ \\
\hline $\begin{array}{l}\text { O trabalho como } \\
\text { empreendedor }\end{array}$ & $\begin{array}{l}\text { Como você̂ identifica uma oportunidade? } \\
\text { Vocề sente dificuldade em solucionar problemas que surgem } \\
\text { durante o processo de comercialização? } \\
\text { Como você̂ lida com o fracasso? } \\
\text { Vocề se envolve com a rotina da comercialização, desde o plantio } \\
\text { até a venda? } \\
\text { Você é membro de grupos/associações ou cooperativas? } \\
\text { Como é que vocề tem acesso às informações sobre o que está } \\
\text { acontecendo no processo produtivo e na comercialização? } \\
\text { Vocề tem acesso a informações tecnológicas sobre produção e } \\
\text { venda de caju? Elas são utilizadas? } \\
\text { Como você lida com a incerteza? }\end{array}$ \\
\hline Relações & $\begin{array}{l}\text { O que vocề acha das relações externas com outros produtores? } \\
\text { Qual é a sua relação com os grandes produtores? }\end{array}$ \\
\hline Encerramento & $\begin{array}{l}\text { Comente sobre as políticas públicas disponíveis para o seu } \\
\text { empreendimento. } \\
\text { O que vocề diria para alguém que esteja pretendendo começar a } \\
\text { produzir/comercializar caju? } \\
\text { Há algo mais que você gostaria de dizer, que nós não abordamos? }\end{array}$ \\
\hline
\end{tabular}

Fonte: Elaboração dos autores (2018).

\subsection{Categorias de Análise}

A pesquisa de campo desenvolvida buscou obter informações sobre os produtores rurais, a rotina de comercialização de seus produtos e suas práticas empreendedoras. As categorias de análise estão apoiadas na abordagem microeconômica proposta por Pato e Teixeira (2016) apresentada no quadro 1.

\subsection{Abordagem da Análise dos Dados}

Para proporcionar maior profundidade de análise a partir da compreensão do contexto do problema, e com intuito de oferecer um panorama mais amplo sobre a situação, o 
tratamento dos dados deu-se através da análise interpretativa, em que se buscou evidenciar pontos em comum na fala dos entrevistados, bem como confrontá-la com a literatura estudada.

\section{ANÁLISE E DISCUSSÃO DOS RESULTADOS}

\subsection{Perfil Empreendedor dos Produtores}

Quando questionados sobre sua autoimagem, principalmente como produtor rural, somente 1 produtor, da vila Rio de Janeiro, não soube responder; segundo ele, "eu deixo que alguém me julgue, não gosto de auto me julgar, não".

Os outros produtores se classificaram como pessoas persistentes, inovadoras, que gostam do que se propõem a fazer e, principalmente, realizadas. "Eu me vejo $100 \%$ realizado" (produtor da vila Sergipe). Conforme o produtor da vila Amazônia, "Eu me sinto uma pessoa feliz e experiente, até porque faz muitos anos que eu trabalho com cajueiro e sempre troco experiências com os técnicos da EMATER". O produtor da vila Paraná afirma ser uma pessoa persistente e que gosta de insistir nas coisas que ele faz e acredita. Já o produtor da vila São Paulo sente-se uma pessoa realizada: “... eu trabalhei honestamente, graças a Deus, a vida inteira. Sofri muito em terras dos outros, aí em 1990 eu comprei um lote na Serra do Mel e estou satisfeito, minha família está estruturada".

Constata-se que os produtores são convergentes com as vertentes apresentadas pela política de desenvolvimento rural (Alves, 2008; Deponti, 2010; Pereira, 2014), pois se fixaram em suas terras, desenvolveram suas atividades, lutaram pela sobrevivência de suas famílias e, atualmente, estão realizados em seus negócios. Apesar dos osbstáculos, mostram-se persistentes em seus cotidianos, em prol do melhoramento em seus meios habitacionais, em suas atividades e, principalmente, na qualidade de vida de suas famílias. Conforme Frank Ellis, elucidado por Deponti (2010), o desenvolvimento rural consiste em um conjunto de práticas voltadas à redução da pobreza e ao combate da vulnerabilidade e objetiva o bem-estar social. Sob a ótica do empreendedorismo, McClelland defende, na ação comportamental do empreendedorismo, que essas ações voltadas para a mudança da realidade social é uma das características que mais se destacam no perfil empreendedor (Gimenez et al., 2008).

Nessas terras, os produtores começaram a plantar cultura de subsistência, como feijão, milho e mandioca, e nos intervalos dessas plantações deram início à cajucultura, que fazia parte do plano de projeção do município, para gerar receita extra. Conforme Moreira (2011), essa alternativa servia como uma fonte de renda e viabilizaria as atividades desses produtores no período de entressafras dessas culturas, além de ter um desenvolvimento produtivo elevado sob condições climáticas de baixo regime pluvial e em épocas de sequeiro.

Peter Drucker acredita que o empreendedor almeja por modificações, responde a elas e as identifica como oportunidades (Gimenez et al., 2008, p. 25). Os produtores enxergaram na nova produção de entressafras uma alternativa de aumentar o ganho transformando-se em empreendedores (McElwee, 2006).

Muitos desses produtores já haviam produzido antes de ocupar as terras de Serra do Mel, mas outros começaram a partir do incentivo de outros produtores, já que viram a rentabilidade 
da produção. Conforme Souza e Elesbão (2011), para tentar superar as dificuldades, diversas estratégias do desenvolvimento rural estão voltadas para os incentivos de ações empreendedoras e inovadoras que viabilizam o surgimento de alternativas de rendas complementares, assim como permitem a inserção no mercado de um grande número de atividades.

O produtor da vila Mato Grosso relata que começou a produzir caju por um acaso: "quando eu cheguei aqui, já existia o projeto. A base sustentável de Serra do Mel sempre foi o cajueiro, e eu continuei. Peguei um lote 'ematado' ${ }^{4}$ que me fez sofrer demais. Desse sofrimento, fiz até um verso", o qual foi transcrito aqui:

Cheguei aqui em 1990, o meu lote era uma mata

O cajueiro era raquítico, não valia uma batata

Para aterrar o meu sonho, veio mais uma seca ingrata.

"Aí, eu continuei trabalhando, fui desmatando e plantando... hoje, eu estou com mais de 40 ha de cajueiro e, graças a Deus, meus cajueiros morreram muito pouco".

O produtor da vila São Paulo relata que já plantava antes de chegar à Serra do Mel, e começou a plantar no município por identificar uma grande oportunidade de desenvolvimento econômico e social, conforme ele descreve: "eu morei no município de Severiano Melo e lá o pessoal plantava caju, aí eu passei lá quatro anos, e no canto em que eu plantava o cajueiro era para os outros, aí quando o caju começou a 'safrejar' ${ }^{5}$ eu deduzi: ah, aqui é ouro. Aí fui pra Serra do Mel, comprei um pedaço de terra lá e comecei a plantar caju". O produtor ainda relata que ele sempre vem obtendo lucros com essa plantação, apesar das dificuldades decorrentes da seca.

Dessa mesma forma começou também o produtor da vila Pará, conforme seu relato : "quando eu cheguei em Serra do Mel, em 1996, já existia área de cajueiro. Aí pronto, eu me adaptei e fiquei comercializando castanha também". Já o produtor da vila São Paulo começou a plantação de cajueiros no município através de uma firma da Suíça, na qual ele trabalhava, que concedeu auxílio aos produtores. Ele deu continuidade ao trabalho e permaneceu até hoje, também afirmando que, apesar dos obstáculos, não houve um ano em que tivesse prejuízo.

Conforme Vale (2014) e Ribeiro (2009), o empreendedor também tinha o perfil de ser inovador, competitivo, ágil e perspicaz para aproveitar as oportunidades. Constata-se que, além desse contexto de exclusão social e de luta pela legitimidade de suas atividades, o empreendedorismo seja decorrente do surgimento de novas empresas, orientadas por práticas inovadoras, assim como de novos negócios. Esses relatos demonstram que esses produtores têm uma relação de pertencimento ao lugar. Como propõe Tibério (2016), trata-se de empreendedorismo rural que tem uma relação endógena com o lugar.

Verifica-se que os relatos dos produtores sobre a iniciação da cajucultura estão relacionados a um aproveitamento de oportunidades. Segundo dados do IBGE (2013), havia um

\footnotetext{
${ }^{4}$ Pedaço de terra que se encontra com vegetação. Torna-se necessário realizar um preparo da área para que possa começar uma plantação.

${ }^{5}$ Consiste em sinônimo de colheita.
} 
projeto de ocupação nas terras de Serra do Mel, e esse projeto continha a prática da cajucultura. Logo, muitos produtores viram na ocupação dessas terras uma oportunidade de produzir, empreender e, consequentemente, conseguir uma inserção no mercado, já que muitos trabalhavam para outros produtores e/ou grandes empresas do agronegócio. Essa forma de conceber a atividade produtiva alinha-se ao conceito proposto por McElwee (2006), o qual considera que o empreendedor rural, além do gerenciamento, está preocupado com o aproveitamento de oportunidades e inovação.

Eles acreditaram no projeto, apesar dos riscos de não haver a prosperidade projetada, e ainda continuam acreditando, apesar das pragas, da estiagem e da falta de conhecimento técnico que, segundo todos os produtores, são os maiores obstáculos enfrentados da cajucultura de Serra do Mel atualmente. Logo, constata-se mais uma característica empreendedora nos produtores, pois, conforme Ribeiro (2009), no século XX, alguns estudos já definiam o indivíduo empreendedor como aquele que atuava em mercados imperfeitos e que suas decisões eram duvidosas, já que estavam sujeitas a erros, devido à escassez de informações. Entretanto, o empreendedor também tinha o perfil de ser inovador, competitivo, ágil e perspicaz para aproveitar as oportunidades.

Quando questionados sobre quais os maiores obstáculos enfrentados na produção, as respostas foram unânimes: a seca e a mosca-branca. "Hoje em dia, o maior problema do produtor de castanha de Serra do Mel é a estiagem. Cada produtor produzia em média de 10.000 kg a 15.000 kg de castanha, mas hoje, a gente não produz nem perto disso. A vila Piauí já perdeu mais de $85 \%$ dos seus cajueiros" (produtor da vila Piauí). O produtor da vila Ceará também afirma que, atualmente, o maior problema é a praga e, em segundo lugar, a seca. Conforme o produtor da vila Alagoas, esses problemas já devastaram parte dos seus cajueiros, diminuindo a sua produção em menos da metade. Essas dificuldades evidenciam a influência do contexto que envolve a cajucultura, pois, como afirma Henderson (2002), o empreendedorismo rural está articulado aos problemas relacionados à indústria e à geografia. No caso aqui analisado, a geografia (ausência de chuva) e a indústria (oscilação de preço da castanha) são fatores que estão além da capacidade individual do agricultor.

Por outro lado, apenas um produtor, o da vila Brasília, declarou ver como um dos seus maiores problemas, além desses dois citados anteriormente, a falta de mão de obra.

[...] a minha maior dificuldade, hoje, é a falta de gente pra trabalhar, gente que tenha um conhecimento desse sistema, gente com garra pra enfrentar mesmo, sabe?! O povo não quer mais trabalhar, não. Em relação à mosca-branca, é combater, juntamente com técnicos da EMATER, alguns agrônomos e também com o conhecimento que a gente tem, e a seca, que Deus nos abençoe, como sempre nos abençoou, porque, com toda essa dificuldade, a gente ainda continua produzindo e sem prejuízos.

Os maiores obstáculos enfrentados pelos produtores é apresentado na figura abaixo. 


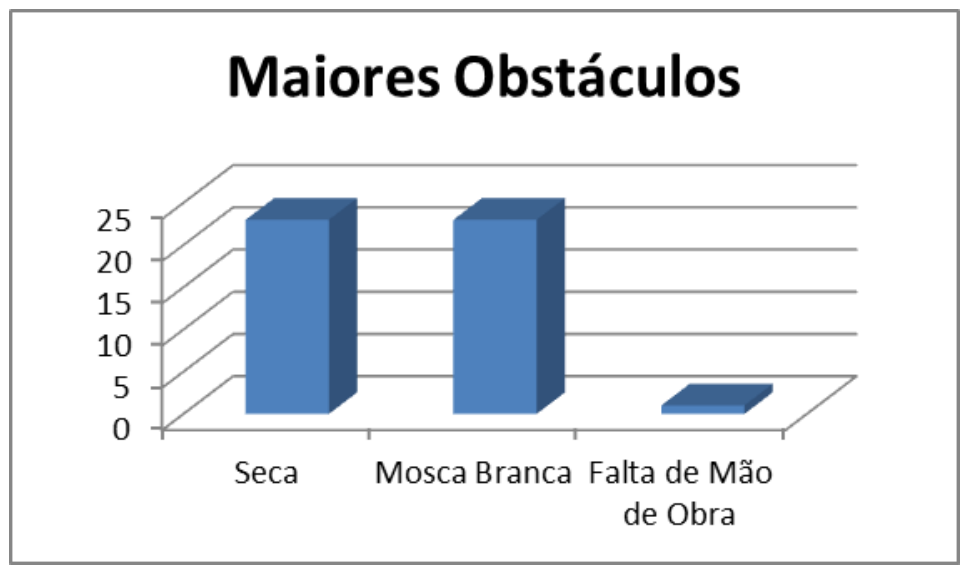

Figura 3 - Obstáculos dos produtores Eixo $x$ - Número de produtores

Eixo y-Obstáculos enfrentados na produção

Fonte: Elaboração dos autores (2018).

Constata-se que há uma discordância entre este e os outros produtores a respeito da rentabilidade de suas produções. Muitos produtores afirmam que suas produções de caju já não estão tão lucrativas assim, pois estão acontecendo muitas mortes de cajueiros por causa das pragas e da estiagem, alguns, inclusive, deixaram de produzir por não ter mais recursos. Entretanto, os grandes produtores, de suas respectivas vilas, elogiam a realidade da comercialização. O produtor da vila Maranhão chegou a afirmar que a castanha só perde para um produto, em termos de valor, o ouro.

Pode-se analisar que a característica primordial para a separação desses dois grupos é a busca por alternativas e oportunidades. Segundo relatos dos produtores entrevistados, quando esse problema da seca teve início, há cerca de quatro anos, eles já começaram a se preparar para a realidade negativa que estava por vir, sendo uma das alternativas armazenar a castanha, pois não é um produto perecível e pode ser armazenado por um bom tempo. Essa estratégia foi tomada visando a uma elevação dos preços quando a demanda fosse maior que a oferta.

Com a morte dos cajueiros e com a estiagem, a produção de caju caiu de uma forma avassaladora, então, muitos produtores não colhiam mais uma quantidade satisfatória. Conforme o produtor da vila Minas Gerais, são necessários $9 \mathrm{~kg}$ de caju (pedúnculo) para se alcançar $1 \mathrm{~kg}$ de castanha (fruto). Logo, para não perderem seus clientes e suas dinâmicas de comercialização, muitos desses produtores passaram a importar dos estados do Ceará e do Piauí os frutos para realizarem o processo de beneficiamento da castanha. Inclusive, segundo o produtor da vila Pará, esses pequenos produtores que pararam suas produções por conta desses obstáculos atualmente realizam esses serviços de beneficiamento da castanha para os grandes produtores.

Essas ações podem ser analisadas através das três vertentes apresentadas por Gimenez et al. (2008). Drucker, em sua visão administrativa do empreendedorismo, afirma que o empreendedor almeja por modificações, responde a elas e as identifica como oportunidades, como ocorreu com os produtores de castanha e as mudanças que eles enfrentaram para poderem se manter ativos no mercado. Já a vertente de Schumpeter defende a visão econômica da atividade empreendedora, pois essas estratégias foram tomadas para que as rendas de suas 
produções rurais não declinassem. Quando analisadas conforme a vertente de McClland, que defende uma visão comportamental do empreendedorismo, infere-se que essas ações só foram concretizadas porque havia uma identificação muito grande dos produtores de castanha com as suas atividades.

Essas ações dos agricultores analisados condizem com as características do perfil que Miner (1998) denominou de realizador, que é aquele sujeito que está sempre em busca de novas ideias e adora estar envolvido em cenários de mudanças, assim como dedica-se a solucionar problemas e administrar crises. Para o autor, os realizadores são os únicos que realmente devem atuar como empreendedores para obter sucesso, pois poderão fracassar em outros cenários. Os produtores necessitaram criar ideias imediatas para se manterem em seus cenários de comercialização, do mesmo modo que precisam ter uma desenvoltura para lidar com os problemas decorrentes da seca e das pragas. Não fracassaram nesse aspecto, mas podem fracassar em outros.

A figura 4 retrata a percepção que os produtores têm de suas características empreendedoras.

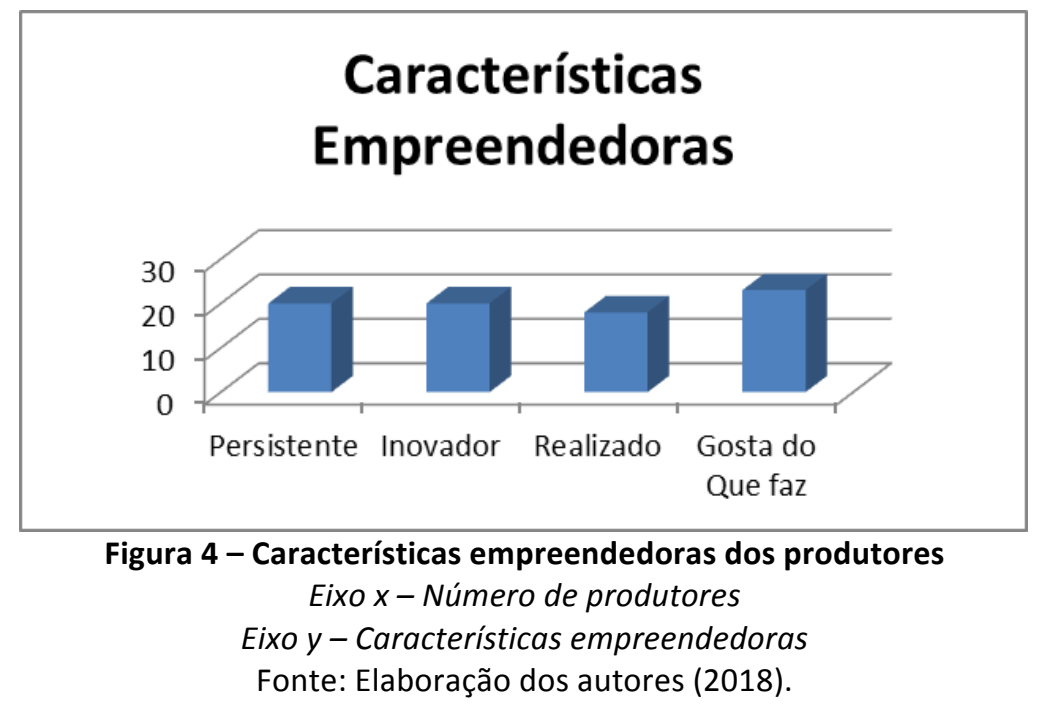

Por isso, quando questionados sobre como lidam com o fracasso, os produtores foram unânimes em afirmar que nunca lidaram com esse fator. E que não sentem dificuldades em solucionar os problemas, só não há o que fazer com as pragas e a seca. Essa característica de ter facilidade ao conduzir situações improváveis e de não acabar com o negócio por conta de obstáculo, Miner (1998) denomina de empreendedor com perfil de realizador, que é um sujeito capaz de solucionar problemas e administrar crises.

Constatou-se que esses produtores rurais não recebem nenhum auxílio governamental para enfrentarem seus problemas ou buscarem outras alternativas, conforme fala o produtor da vila Paraná: "nós não recebemos nenhum auxílio, só Deus mesmo, nos dando força e saúde para trabalhar". 


\section{CONSIDERAÇÕES FINAIS}

A pesquisa realizada com os produtores de castanha de maior destaque do município de Serra do Mel/RN teve como objetivo principal a identificação das estratégias gerenciais desenvolvidas por eles, a fim de identificar se possuem características de empreendedorismo rural.

Partindo de uma perspectiva microeconômica (Pato \& Teixeira, 2016), os traços psicológicos demonstram a motivação desses agricultores em desenvolver a atividade. Por outro lado, constatam-se características relacionadas ao desenvolvimento de mercados, como no caso do armazenamento temporário da castanha e a compra dos frutos de outros estados para realizar o processo de beneficiamento e vender a castanha. Ambas foram estratégias oportunas visualizadas pelos produtores para atenderem a suas demandas a longo prazo e não permitirem que seus negócios fossem drasticamente afetados pelos obstáculos enfrentados nos últimos anos, como a seca, as pragas e a morte de cajueiros, além de oferecer ajuda a outros produtores que não têm condições de seguir com a comercialização, concedendo-lhes empregos no processo de beneficiamento, ou seja, estratégias de gerenciamento que visam manter a competitividade desses empreendimentos.

Dessa forma, considerando que o empreendedor rural é aquele que ocupa em tempo integral as atividades relacionadas a sua propriedade, mas sobretudo preocupa-se com o risco e a inovação (McElwee, 2006), observa-se que esses agricultores se aproximam dessa perspectiva.

Sobre o processo de comercialização da castanha, percebe-se que os produtores possuem atividades semelhantes, pois realizam todo o processo de beneficiamento da castanha e a vendem para seus respectivos clientes. Alguns produtores vendem sua produção através de cooperativas; outros vendem por conta própria. Em ambas alternativas, os produtores estão sempre em busca de oportunidades de melhoramento de suas produções. Alguns, inclusive, já estão observando oportunidades de comercializar o pedúnculo também.

Conforme a ação administrativa do empreendedorismo defendida por Drucker (Gimenez et al., 2008), o empreendedor almeja por modificações, responde a elas e as identifica como oportunidades, assim como ressalta Ribeiro (2009), que no século XX alguns estudos já definiam o indivíduo empreendedor como aquele que atuava em mercados imperfeitos e que suas decisões eram duvidosas, já que estavam sujeitas a erros, devido à escassez de informações. Entretanto, o empreendedor também tinha o perfil de ser inovador, competitivo, ágil e perspicaz para aproveitar as oportunidades. Realidade semelhante aos dos produtores, pois atuam em mercados imperfeitos e incertos, principalmente por conta da seca, e buscam nessas mudanças, oriundas das adaptações para manter-se inseridos no mercado, oportunidades de desenvolvimento.

Em relação aos possíveis incentivos governamentais, os produtores de castanha afirmaram ser completamente desassistidos por essas políticas e não receberem nenhum auxílio financeiro para subsidiar suas atividades. Se essa realidade se modificasse, de modo que os produtores passassem a receber algum recurso financeiro, se tornaria mais viável a solução de algumas das dificuldades enfrentadas por eles atualmente. 
Uma limitação da ação empreendedora desses agricultores está relacionada ao estabelecimento de alternativas sugeridas por McElwee (2006), no sentido da diversificação, inclusão de negócios não agrícolas, processamento de alimentos, que poderia oferecer maior desempenho da produção e minimizar os riscos decorrentes dos obstáculos como pragas e estiagens.

A cajucultura, como desenvolvida por esses agricultores, não conseguiu produzir um mix de indústria e geografia (Henderson, 2002) que favorecesse sua competitividade.

Por fim, para próximos estudos, sugere-se que a pesquisa seja ampliada com a inclusão de outras cidades produtoras de castanha do Rio Grande do Norte em busca de responder ao mesmo objetivo deste estudo: identificar se as características de gestão desses produtores são empreendedoras, assim como pesquisar nos órgãos competentes o motivo da escassez de programas de auxílios voltados para esses produtores, tendo em vista que a cajucultura tem um destaque econômico no estado do Rio Grande do Norte.

\section{REFERÊNCIAS}

Abramovay, R. Agricultura e desenvolvimento rural. Recuperado em 19 junho, 2015, de http://ricardoabramovay.com/agricultura-e-desenvolvimento-rural/.

Alves, A. F. (2008). Do Desenho à Implementação de projetos de desenvolvimento rural sustentável: interfaces e negociações no Projeto Vida na Roça (Paraná). Tese de doutorado, Universidade Federal de Santa Catarina, Florianópolis, SC, Brasil.

Alves, C. (2015). Serra do Mel: de próspera a um cenário cinza! Recuperado em 14 julho, 2015, de http://www.mossorohoje.com.br/coluna/retratodooeste/25/25-02-2015/Serra-do-Mel:-Depr\%C3\%B3spera-a-um-cen\%C3\%A1rio-cinza!

Andrade, M. P., Martins, M. G., \& ladanza, E. do E. S. (2014). Agroindústrias familiares: políticas públicas e desenvolvimento rural. Anais do Encontro da Sociedade Brasileira de Economia, Administração e Sociologia Rural (SOBER), Goiânia, GO, Brasil, 52.

Andrade Neto, J. C. de (2006). Competitividade na pequena produção agroindustrial: estudo na agroindustrial da castanha do caju. Dissertação de mestrado, Universidade Federal do Rio Grande do Norte, Natal, RN, Brasil.

Arnould, G. (2011). Empreendedorismo rural: um estudo sobre a inserção do técnico em agropecuária, egresso do IFRS - Campus Sertão. Dissertação de mestrado, Universidade de Brasília, DF, Brasil.

Banco do Nordeste - BNB. Análises e considerações sobre a economia e setores produtivos do Nordeste. Recuperado em 7 setembro, 2016, de http://www.bnb.gov.br/projwebren/Exec/livroPDF.aspx?cd_livro=179.

Bastos, F. Agricultura familiar no Nordeste: um desafio às políticas públicas. Recuperado em 27 junho, 2015,

http://www.fundaj.gov.br/index.php?option=com_content\&view=article\&id=609\%3Aagricul tura-familiar-do-nordeste-um-desafio-as-politicas-publicas- $\&$ catid=58\&ltemid= $=414$. 
Carvalho, D. (2015). Estiagem afeta produção de castanha em Serra do Mel. Recuperado em 14 julho, 2015, de http://gazetadooeste.com.br/estiagem-afeta-producao-de-castanha/.

Chaves, R. de Q., Magalhães, A. M., Benedetti, O. I. S., Blos, A. L. F., \& Silva, T. N. da (2010, setembro, dezembro). Tomada de decisão e empreendedorismo rural: um caso da exploração comercial de ovinos de leite. Revista Brasileira de Gestão e Desenvolvimento Regional, 6(3), 3-2.

Clemente, E. C., Hespanhol, A. N. (2013, setembro, dezembro). Questões do desenvolvimento rural: perspectivas de dinamização do campo a partir de atividades não agrícolas na região de Jales (SP). Bol. Goia. Georgr. (On-line). (Vol. 33, n. 3, pp. 457-476). Goiânia.

Companhia Nacional de Abastecimento - CONAB. Panorama sobre a cajucultura no Ceará. $\begin{array}{lllll}\text { Recuperado em } & 13 & \text { julho, 2016, de }\end{array}$ http://www.conab.gov.br/OlalaCMS/uploads/arquivos/13_12_20_14_51_36_panorama_da _cajucultura_no_ceara_2013.pdf.

Conterato, M. A. (2008). Dinâmicas regionais do desenvolvimento rural e estilos de agricultura familiar: uma análise a partir do Rio Grande do Sul. Tese de doutorado, Universidade Federal do Rio Grande do Sul, Porto Alegre, RS, Brasil.

De Jesus Santos, G., Muquiutti, E., Costa, W. L., Said, R. A., \& Junior, D. M. P. (2017). Empreendedorismo feminino no mercado de trabalho: uma análise de seu crescimento/Female entrepreneurship in the labor market: an analysis of its growth. Brazilian Journal of Development, 3(3), 450-464.

Deponti, C. M. (2010). Intervenção para o desenvolvimento rural: o caso da extensão rural pública do Rio Grande do Sul. Tese de doutorado, Universidade Federal do Rio Grande do Sul, Porto Alegre, RS, Brasil.

Dornelas, J. (2012). Empreendedorismo: transformando ideias em negócios (4. ed., 260 p.). Rio de Janeiro: Elsevier.

Empresa de Pesquisa Agropecuária - EMPARN. Recuperado em 14 julho, 2015, de www.emparn.rn.gov.br.

Figueiredo, A. M., Souza Filho, H. M., \& Guanziroli, C. E. Poder de mercado e transmissão de preços na cajucultura brasileira. Recuperado em 9 julho, 2015, de http://www.sober.org.br/palestra/13/276.pdf>.

Food and Agriculture Organization - FAO. FAOSTAT - Food and Agriculture Organization of the United Nations. Recuperado em 9 julho, 2015, de faosfat.fao.org/site/567/DesktopDefault.aspx?PagelD=567\#ancor.

Gil, A. C. (2007). Como elaborar projetos de pesquisa (4. ed.). São Paulo: Atlas.

Gimenez, F. A. P., Ferreira, J. M., \& Ramos, S. C. (2008). Configuração empreendedora ou configurações empreendedoras? Indo um pouco além de Mintzberg. Anais do Encontro da Anpad, 32., Rio de Janeiro, RJ.

Gomes, T. C. L. (2007). Aglomerações produtivas e desenvolvimento local: arranjos produtivos locais da amêndoa da castanha-de-caju nos municípios de Barreira e Pacajus no estado do Ceará. Tese de doutorado, Universidade Federal do Rio Grande do Sul, Porto Alegre, RS, Brasil. 
Guanziroli, C. E. et al. (2009). Entraves ao desenvolvimento da cajucultura no Nordeste: margens de comercialização ou aumentos de produtividade e de escala. Revista Extensão Rural, 16 (18).

Guanziroli, C. H., Souza Filho, \& Valente Junior, A. S. Cadeia produtiva do caju no Nordeste brasileiro. Recuperado em 13 julho, 2015, de http://www.agenciaprodetec.com.br/prosa-averbo/100-cadeia-produtiva-do-caju-no-nordeste-brasileiro.html.

Guimarães, T. B. C. (2004). Análise epistemológica do campo do empreendedorismo. Anais do Encontro Nacional dos Programas de Pós-Graduação em Administração, 28.

Henderson, J. (2002). Building the rural economy with high-growth entrepreneurs. Economic Review-Federal Reserve Bank of Kansas City, 87(3), 45-75.

Hisrich, R. D., Peters, M. P., \& Shepherd, D. A. (2014). Empreendedorismo (9. ed., 456 p.). Porto Alegre: AMGH.

Instituto Ambiental do Paraná - IAP. CAR-PR - Conceitos. Recuperado em 13 julho, 2015, de www.iap.pr.gov.br/modules/conteudo/conteudo.php?conteudo=1326.

Instituto Brasileiro de Geografia e Estatística - IBGE. Rio Grande do Norte - Serra do Mel. $\begin{array}{lllll}\text { Recuperado } & \text { em julho, 2016, de }\end{array}$ http://ibge.gov.br/cidadesat/painel/historico.php?codmun=241335\&search=rio-grande-donorte\%7Cserra-do-mel\%7Cinphographics:-history\&lang=_EN.

Machado, A. G. et. al. (2008). Multifuncionalidade e pluriatividade como alternativas de desenvolvimento da agricultura familiar no Brasil. Desafio, 9 (17), 19-30.

Maia, C. M., Filippi, E. E., \& Riedl, M. (2009, janeiro, abril). Território, ruralidade e desenvolvimento regional. Revista Brasileira de Gestão e Desenvolvimento Regional, 5 (1), 191-202. Taubaté.

Maia Neto, A. L. (2008). A experiência da cooperativa de empreendedores rurais de Jussara: subsídios para políticas de desenvolvimento territorial sustentável no semiárido. Dissertação de mestrado, Universidade de Brasília, Brasília, DF, Brasil.

March, J. G., \& Olsen, J. P. (2008, novembro). Neo-institucionalismo: fatores organizacionais na vida política. Rev. Sociol. Polít., 16(31), 21-142.

Martes, A. C. B. (2010). Weber e Schumpeter: a ação econômica do empreendedor. Brazilian Journal of Political Economy, 30(2), 254-270. Recuperado de https://dx.doi.org/10.1590/S0101-31572010000200005.

MCelwee, G. (2006). Farmers as entrepreneurs: developing competitive skills. Journal of Developmental Entrepreneurship, 11(03), 187-206.

Medonça, P. M. E. de, Alves, M. A., \& Campos, L. C. (2010, janeiro, junho). Empreendedorismo institucional na emergência do campo de políticas públicas em HIV/AIDS no Brasil. RAE Revista de Administração de Empresas, 9(1).

Mielitz, C. Desenvolvimento agrícola e questão agrária. Recuperado em 19 junho, 2015, de http://www.fpabramo.org.br/forum2013/wp-content/uploads/2013/11/7Mielitz.pdf>.

Miner, J. B. (1998). Os quatro caminhos para o sucesso empresarial: como acertar o alvo no mundo dos negócios. São Paulo: Futura, 305 p. 
Ministério do Meio Ambiente - MMA. Caderno setorial de recursos hídricos: agropecuária. $\begin{array}{lllll}\text { Recuperado em } & 9 & \text { julho, 2015, de }\end{array}$ http://www.mma.gov.br/estruturas/161/_publicacao/161_publicacao23022011030305.pdf.

Miyazaki, J., Nazzari, R. K., Bertolini, G. R. F., Gaffuri, J., Schimitd, R. M., \& Teodoro, P. A. V. B. (2004). Capital social e empreendedorismo rural: a agricultura familiar no oeste do Paraná. Recuperado em 29 março, 2017, de http://www.unioeste.br/campi/cascavel/ccsa/IVSeminario/IVSeminario/Artigos/11.pdf.

Moreira, R. C. (2011). Reações de clones de cajueiro comum à resinose. Dissertação de mestrado, Universidade Federal do Ceará, Fortaleza, CE, Brasil.

Moura, M. L. S., \& Ferreira, M. C. (2005). Projetos de pesquisa: elaboração, redação e apresentação. Rio de Janeiro: EdUERJ.

Nogueira, A. de P., Torres, G., Almeida, M. Y. de, Ambrosio, R. A. H., \& Nogueira, I. C. R. F. (2011). Perfil empreendedor: um estudo de caso do fundador da Unoeste em Presidente Prudente. Anais do Colloquium Humanarum, 1, 01-08.

Nunes, E. M., França, A. R. M., Silva, M. R. F. da, Sá, V. C. de, \& Gurgel, I. A. (2018, maio, agosto). Arranjos produtivos em dinâmicas de desenvolvimento regional: a cadeia da cajucultura no território Açu-Mossoró (RN). Redes - Santa Cruz do Sul: Universidade de Santa Cruz do Sul, 23(2), 187-209.

Oliveira, E. M. (2004). Empreendedorismo social no Brasil: atual configuração, perspectivas e desafios - notas introdutórias. Revista da $F A E, 7(2)$.

Padua, J. B., Schlindwein, M. M., \& Gomes, E. P. (2013, julho, dezembro). Agricultura familiar e produção orgânica: uma análise comparativa considerando os dados dos censos de 1996 e 2006. Interações, 14(2), 225-235.

Pato, M. L., \& Teixeira, A. A. (2016). Twenty years of rural entrepreneurship: a bibliometric survey. Sociologia Ruralis, 56(1), 3-28.

Pereira, V. C. (2014, abril). Elementos para pensar a contribuição do desenvolvimento rural para a conservação do bioma Pampa. Mundo Agrário, 15(28), 01-26.

Ribeiro, R. C. L. (2009). Personalidade empreendedora, recursos pessoais, ambiente, atividades organizacionais, gênero e desempenho financeiro de empreendedores tomadores de microcrédito. Dissertação de mestrado, Universidade Estadual do Ceará, Fortaleza, CE, Brasil.

Froehlich, J. M., \& Vivien, D. (Org.). (2006). Desenvolvimento rural - tendências e debates contemporâneos. ljuí: Unijui.

Schmidt, S., \& Bohnenberger, M. C. (2009, julho, agosto). Perfil empreendedor e desempenho organizacional. RAC - Revista de Administração Contemporânea, 13(3), 450-467.

Schneider, C. P. (2008). Agricultura familiar e empreendedorismo: um estudo sobre trajetórias de jovens egressos do centro de desenvolvimento do jovem rural (CEDEJOR) no vale do Rio Pardo/RS. Dissertação de mestrado, Universidade Federal do Rio Grande do Sul, Porto Alegre, RS, Brasil.

Souza Filho, H. M., Guanziroli, C. E., Figueiredo, A. M., \& Valente Junior. A. S. (2009). Competitividade ameaçada: análise da estrutura de governança do agrossistema brasileiro 
da amêndoa de castanha de caju. Anais do Encontro da Sociedade Brasileira de Economia, Administração e Sociologia Rural (SOBER), 47, 01-20, Porto Alegre.

Souza Filho, H. M., Batalha, M. O. (Orgs.). (2005). Gestão integrada a agricultura familiar. São Carlos: Eduscar.

Banco Nacional do Desenvolvimento - BNDS. Desenvolvimento rural sustentável. Recuperado em 15 julho, 2015, de www.bndes.gov.br/SiteBNDES/export/sites/default/bndes_pt/Galerias/Arquivos/conhecime nto/livro_debate/3-DesenvRural.pdf.

Souza, M. de, \& Elesbão, I. (2011). Turismo rural: iniciativas e inovações. Porto Alegre: Ed. da UFRGS, $360 \mathrm{p}$.

Souza, A. L. de (2011). Trabalho e desenvolvimento territorial na Amazônia Oriental: a experiência da rede de desenvolvimento rural do Baixo Tocantins (PA). Tese de doutorado, Universidade Federal do Rio Grande do Sul, Porto Alegre, RS, Brasil.

Tibério, B. D. M. (2016). Empreendedorismo rural e pobreza das regiões: uma análise exploratória. Dissertação de mestrado, Universidade do Porto.

Vale, G. M. V. (2014, maio, junho). Empreendedorismo, marginalidade e estratificação social. $R A E$ - Revista de Administração de Empresas, 54(3), 310-321.

Vieira, L. P. (2007). Controle da mosca-branca-do-cajueiro: Aleurodicus cocois (Curtis, 1846) (hemiptera: aleyrodidae), com fungos entomopatogênicos, detergente neutro e óleo vegetal. Tese de doutorado, Universidade Estadual do Norte Fluminense Darcy Ribeiro, Campos dos Goytacazes.

Veiga, J. E. da (2002). Do crescimento agrícola ao desenvolvimento rural. In Castro, A. C. (Org.). Desenvolvimento em debate (Vol. II, pp. 383-409), Rio de Janeiro, RJ: Ed. Mauad/BNDES. 